\title{
Delusional jealousy as defense mechanisms against late-life aging losses
}

\begin{abstract}
This paper presents the development of a delusional jealousy in a 95 year old man who struggled to cope with the loss of his health and the loss of intimate relationships with his young wife. Old age is a journey of physical and emotional survival involving the need to cope with changes, losses and separations. When physical and mental health deteriorates, symptoms of paranoia can appear, some of which can serve as defense mechanisms against aging losses. We suggest that the delusional jealousy of Mr B. aged 95, manifested in rivalry with his wife's son, expressed early symptoms of dementia but their narrative served as a defense mechanism and as a means of adjustments used to maintain control and protect his aging narcissistic self against the accumulating losses of old age.
\end{abstract}

Volume 9 Issue 4 - 2018

\section{Liora BarTur}

Department of Clinical Psychology, Hebrew University, Israel

Correspondence: Liora Bar Tur, Department of Clinical Psychology, Instructor. Senior Lecturer, MA in Family Studies, School of Behavioral Sciences, Academic Studies, The College of Management, Hebrew University, Israel, Tel 039634432, 054 7501050,Email liorab@barak.net.i

Received: March II, 2018 | Published: July 20, 2018

\section{Introduction}

The oldest-old or the old-old population relates to those who are 85 or over. ${ }^{1,2}$ Baltes and Baltes, ${ }^{3}$ Baltes \& Smith ${ }^{4}$ suggest that the oldestold experience a negative change in the balance of gains and losses. This change is a product of aging-related reduction in the scope of physical, cognitive and motivational reserve capacity. To some extent, more than half of those aged 90 suffer from dementia and from a gradual loss of critical qualities of life such as remaining autonomous, functionally independent, retaining their personal identity, social contacts, the ability to carry out their plans, etc. Losing these functions may be hard blow to basic human pride and particularly to an old person's right to live as he or she would wish. Johnson \& Barer $^{5}$ found that the oldest-old tend to have different interpretations of their problems, and the connotations that they attribute to the various events are what enables them to feel that they control their own lives. In fact, an oldest-old person develops a self-concept that is different from the one he had during his younger old age. Instead of being in control and involved in one's life, the adjustments formulated to suit a person's advanced age involve the ability to give up control, to be able to accept a certain measure of dependency upon others, and to cut oneself off from annoying and tension-causing social contacts. Diminishing or diminished functions require some sort of adjustment: the ability to transfer control to others, to be able to endure situations requiring dependency, the ability to disassociate oneself and to adjust one's priorities, putting less emphasis on social stimulation, etc. Smith \& Baltes ${ }^{6}$ claim that the bio-social architectonic planning for human development is not perfect when one refers to the oldestold. The architecture of the life-process reflects a frustrating lack of completeness in the oldest-old. In order to understand the difficulties facing an oldest-old person in making the adjustments, one must examine him in a bio-psycho-social context. Chronological age or physical state are vastly inadequate as an indication for classifying the level of well-being among these individuals. On the whole many people report high level of well-being. The paradox of wellbeing, despite worsening physical, cognitive, and diminished resources, is not yet explained. Empirical findings document some factors associated with well-being, such as those of personality, self-reported health, quality of relationships, and adequacy of economic resources.

\section{Paranoia in old age}

The etiology of the development of paranoia during aging is variegated and therefore, clinical evaluation of such is very important. At times, the paranoia is the result of a deterioration of senses, such as hearing or sight. Paranoid delusions are common in dementia. ${ }^{8}$ These symptoms may be an attempt to fill the void created by the deterioration of one's memory. Paranoia can also develop during old age in people with a compulsive-obsessive disorder, people suffering from personality disorders, particularly schizoid or narcissistic personalities or those who suffered earlier traumas in life. ${ }^{910}$ Paraphrenia has been suggested to be an illness related to older age. A diagnosis of paraphrenia included semisystematized delusions and auditory hallucinations without severe personality or thought disturbances and relatively appropriate affect and behaviours. It is often expressed in isolated incidents of delusion without the appearance of any other symptoms, any neurological disorders or initial affective disorder elements of schizophrenia or Alzheimer's. Despite the occurrence of the paranoid disorder, the person's personality is retained. However, it is no longer found in the DSM or International Classification of Diseases (ICD). People who might otherwise meet criteria for this diagnosis are diagnosed with delusional disorder. ${ }^{8}$ Delusional jealousy is considered as a psychotic syndrome characterized by a belief in the infidelity of one's spouse that reaches delusional intensity. Although delusional jealousy has been described in relation to organic psychosis, little is known concerning the actual role of delusional jealousy in dementia.. In dementia, delusional jealousy may develop more easily in patients who have dementia with Lewy bodies and those with coexisting serious physical disorders. ${ }^{11}$ Zarit \& Zarit ${ }^{12}$ call such paranoia, evident in people who have a history of stable marriages and stability at work, encapsulated paranoid delusion. Usually, the reference is to a strongly distorted belief that the content of this paranoia is banal and related to reality. The frequent delusions are expressed by thoughts of persecution manifested in paranoid behavior or attitude towards the environment. These delusions are derived from fear and feelings of internal threat which are shifted and projected, turning into an external enemy or threat. The combination of delusional belief and lack of insight is very disturbing to other people. 
Molinari \& Chacko $^{13}$ claim that the development of symptoms of paranoia in old people is usually the result of the use of projection as a defense mechanism against sorrow or the perception that one is losing control and one's autonomy. These feelings are characteristic of old people who are restricted by their physical condition and are dependent on the environment. It should be pointed out that paranoid delusions based on a sense of betrayal often appear in situations where one of the members of the couple is physically handicapped, disabled, while the other is still young and healthy. A young caregiver in the house, or residing in a nursing home could become the trigger for very strong feelings of jealousy and loss of control that give rise to extreme anxiety, often developing into paranoia. ${ }^{14}$ It seems that these symptoms protect the oldest-old from even more severe feelings of despair and depression resulting from losses and the fear of becoming dependent as was experienced during the period preceding the outbreak of paraphrenic symptoms. In many cases, these delusions give the aged control over members of the family, or the staff of the institution in which they reside, any of whom can feel helpless or controlled by them. They thus succeed in ensuring that the environment invests energy and attention in them. It is difficult to ignore their distress, and this enables them to retain a certain measure of self-worth, where instead of admitting and giving in to their weakness or their incapacities, thereby feeling helpless and despairing, they project these feelings onto their surroundings through accusations and attacks, causing their environment, by using projective identification, to feel their despair, their frustration and their anger.

\section{Implications for treatment}

Oldest-old people who find it difficult to adjust to losses, particularly if they have some personality disorders, might, during the aging process, develop symptoms of paranoia as a result of their inability to depend on their surroundings, and their fear of losing their independence. The type of paranoid symptoms depends on the various resources at their disposal, particularly, their cognitive condition. As a rule, the delusion is presented in a coherent and organized manner, with a logical and clear explanation for the "enemy"s behavior. This is the key to understanding the old person's inner conflict or distress. During a therapy session with an old person suffering from paranoia, the initial goal is to support and calm him, since he is in a state of great anxiety. The therapist must gain his trust and become the "good" object that will help him overcome "the bad object - the enemy". The important element in therapy is, first and foremost, listening to the story and its contents. In principle, Zarit \& Zarit ${ }^{12}$ claim that there must be minimal intervention. The objective, therefore, is to become part of the patient's organized and impregnable paranoia. Not to agree with him, but also not to disagree. To relate to his difficult situation, to his distress, to his anxiety, by saying things like: "I can imagine that it is very difficult for you when you feel that you are being cheated or that someone is trying to hurt you. This is undoubtedly very stressful and frightening". The objective is to help the patient increase and nurture his positive self-esteem, his improved self-image; to give him the feeling that he is understood and that someone wishes to help him. He should be encouraged to take advantage of relief through the use of medication, and someone should explain to him that the treatment will help him calm down so that he will have the strength to cope with his difficulties, without giving him the feeling that he is not being believed. A very important part of therapeutic intervention is to calm down the members of the family or the staff nursing the old person. It is important that they understand the significance of the delusions. It assists in understanding the old person's anxiety and the source of his/ her accusations which are, at times, also thrown at them.

\section{Case study}

Mr. B a 95-year old man was seeking marriage counselling due to difficulties in his relationships with his second wife, aged 65. Mr. B, an acclaimed scholar, was married to his first wife for over 60 years with whom he had a distant relationship. He met his second wife, Mrs. $\mathrm{N}$, when she was nursing his sick wife. They married soon after his wife had passed away. At the time, Mr. B was 87 and Mrs. N was 57, a new immigrant from Eastern Europe. Mr. B. was in love and very happy for the first time in his life. The seven years Mr. B and Mrs. $\mathrm{N}$ have been living together have been an enriching and satisfactory experience for the both of them. However, their life of intimacy ended a year before, when Mr. B became ill and his physical condition deteriorated. His wife left their bedroom and refused to continue intimate relationships with him. Mr. B. felt very lonely and rejected. Despite his physical limitations and weakness, Mr. B went out every day to tend to the plants and flowers in the yard of his apartment building. This activity involved responsibility, but its main purpose, as he said, was to keep him in touch with life and with the future. The blooming of a seasonal flower moved him emotionally: "Seasonal flower seedlings - I believe in the future and in a rebirth. I look at them every morning and my heart swells. My life is full. I love life and enjoy life despite the difficulties. I am happy for every day that I wake up. I know that I am living in a paradox. Recently I have become very emotional and am unable to control the crying..." During the last year, as his physical condition deteriorated and physical contact with his wife gradually diminished and eventually stopped, Mr. B's anger and frustration increased. He continued to feel the need for some sort of contact, intimacy, closeness, and when he was denied that, he began to harass and punish her. His need to always be in control found expression in controlling the money she spent, accusing her of being extravagant, demanding she report to him exactly where she was going and when she would be back when she left the house on errands, controlling her telephone calls and in particular, scathingly criticizing her relationship with her son. In addition, during the day he would, as she put it, "harass her by having her go back and forth fulfilling small requests for treatment or attention." He kept complaining that she is failing at "her job" and that she doesn't care about him, despite the fact that she made efforts and tried to do things with great care. "I don't need a nurse, I need a wife" he kept saying.

Mr. B was 95-years old and despite his advanced age and weak, sick body, his "self" was young and full of life. His wife was 65-years old, a relatively young woman, but emotionally, she felt old and sometimes "dead". She took good care of Mr. B. but she was depressed, feeling "dead". "Just imagine that your wife has died," she said to him when he wanted physical contact with her. Mr. B found it hard to forgive her for that and repeated these words often. He also found it difficult to accept that the main reason for her tension could be their relationship, the fact that he was demanding and controlling, a pattern of behavior which was at present essentially negative, while in the past, this pattern was acknowledged as being strong and protective. Mr. B was the smart older man, the one who guided and taught his young wife so many things, who moved her with his great knowledge and his worldencompassing contacts. It was frustrating that he was no longer able to continue running their lives as he had in the past. As time passed Mr. B became completely focused upon himself and his survival. He was anxious, dependent and perceived Mrs. N's absences from the house as rejection and neglect. The tension between the couple was mostly due to Mrs. N's relationship with her son, V who was a goodlooking young man with great personal charm and a good temper. Mr. B complained that when V. comes to visit, his wife comes alive, 
laughs, and seems happy. He accused her of giving V. preferential treatment when she prepared special food for him that Mr. B did not eat. "In my house, I am the king, not V." he said. It was interesting to examine the two conflicting sides of Mr. B. On the one hand, there was wisdom, sharpness, sensitivity, understanding, and an amazing ability to analyze with acceptance and a sense of humor. On the other hand, he acted as a deprived and jealous boy who was constantly comparing himself to his wife's younger son, minutely examining every move made by this boy who was so full of life and charm, and especially sensitive to expressions of affection between his wife and her son. This over-sensitivity was also related to the trauma of his first marriage, clearly expressed when he remembered and mentioned his late wife's absolute devotion to their difficult son and the feeling of betrayal he experienced as a result. As time passed, it seemed that Mr. B's obsessive preoccupation with Mrs. N's son has increased and turned into paranoia. He portrayed a sad picture of an old man whose wife deprives and neglects him in favor of the "young king", as he kept calling him.

It seemed that Mr. B's frustrations and anxieties were turning into delusions. He was confused, the past merging with the present, imagination with reality. He kept talking about events from the past and the present in which he felt that $\mathrm{V}$. is actually planning to get rid of him or to kill him. When I told him that I have difficulties following him, his answer was: "Usually I am clear and rational but sometimes I don't know what is real and what is imaginary."

A month later, Mr. B's condition weakened and he was no longer able to go down to care for the plants in the garden. He tended to sleep a lot, tire easily and often, and during conversations with visitors seemed to be less alert and more indifferent. Nevertheless, anything related to Mrs. $\mathrm{N}$ produced strong feelings. He continued to bully her and accuse her of neglecting him. Two weeks passed, and after another argument between him and Mrs. N, Mr. B asked me to come and see him that very week. During that argument, Mr. B told her that $\mathrm{V}$ was trying to murder him. A plant that the son had brought to Mrs. $\mathrm{N}$ as a present for her birthday was perceived as male phallic symbol, another provocation of the young man who is trying to get rid of him. As time passed, his inappropriate feeling of lack of trust grew stronger. He blamed his wife for being sexually aroused by a doctor who treated her back. "She is tense because she is not gratified sexually" claimed Mr. B while speaking effortlessly. He also continued to blame her son for planning to kill him and for seducing his mother. He referred to a picture that $\mathrm{V}$ had given his mother where he is half-naked, juggling, performing. He pointed to V's nakedness and how he used his body to make a living. He spoke disdainfully, angrily - "I demanded that he remove the hypnotic spell from his mother". Pointing at the plants in his room, Mr. B. looked at me and said that he had turned their garden into a garden with perennials plants because "I expect to look at them for a long time yet. Optimism is part of my personality but I also know that this is not a life worth living. Nevertheless, when I see the flowers, I say how beautiful [they are] but this fight to get rid of this vulgar plant..." [a reference to the plant V had brought]. A few months later Mr. B. passed away.

\section{Discussion}

The focus of our discussion is on the psychological narrative and the person who was struggling with delusional jealousy. Mr. B.'s story is a narrative in two parts. The first part is pure optimism. An 86-year old man falls in love for the first time in his life with a woman who is 30 years younger than him; marry her when he is 87 , content every moment they are together. Their first years are full of experiences and excitements. The story gives hope to many who have not been lucky enough to love. He exemplifies for us how love can develop, even during very old age, how it is accompanied by strong "ageless" feelings, and how it is possible to build a new relationship, even under conditions of physical exhaustion, when cognitive, personal and social resources compensate for the physical weakness. However, the idyll ends at a certain stage, when old age advances and the body becomes weaker and is unable to function autonomously. That is the point at which the delicate balance is lost and the many losses defeat the advantages of the fourth age. It seems that with the physical and cognitive deterioration, there is an emotional and mental withdrawal, followed by symptoms of dementia. Mr. B becomes fearful, suspicious, very frustrated with his condition, and as a result, self-centered and more critical and aggressive. He needs his wife' love and full attention, and cannot tolerate her independence. She feels that she has lost the strong, smart, intelligent (father) figure who gave her shelter. She is devoted to Mr. B and looks after him, but is incapable of relating to him as to a man. Mr. B's clinging to Mrs. N, his jealousy of and for her, the competition he wages with her young son can all be characterized as expressions of psychological processes and unsolvable conflicts from the past that return and float to the surface with a vengeance during later old age. Anne Marie Sandler ${ }^{15}$ compares the pressures of old age to the developmental childhood tasks described by Anna Freud. In both old age and childhood, one has to cope with narcissistic upsets and with crises related to the projection from one developmental stage to another. For example, the longing for a mother, according to Gutmann ${ }^{16}$ is expressed in old age by increased oral needs and a longing for mother's food, when oral needs become a substitute for genital needs. For Mr. B, his preoccupation with food is the center of the existentialist experience. For Mr. B food was means of controlling Mrs. N making comparisons with the way she was feeding her son. According to Bowlby ${ }^{17}$ the need for attachment increases in old age. This can be expressed by the old person as a need for a secure base, seeking a significant figure upon whom he can lean and if possible, trust. Mr. B's clinging to Mrs. $\mathrm{N}$, the anger he felt when she left the house, can be an expression of his anxieties and need for contact to make him feel protected and safe, just as a child becomes anxious when his mother leaves him. Even the Oedipus complex does not end with childhood but continues in different variations during maturity. Jealousy and competition between a child and his bigger and potent father can, in old age, be replaced with jealousy and the feeling of competition the old father feels with regard to his young and strong son. Thus, the interaction of significant issues from the past continues through the developmental stages. ${ }^{18}$ For Mr. B, the feeling of competition and jealousy he may have experienced as a child, and that he later felt for his handicapped son who competed with him, winning the love of his mother, seems to continue in old age with regard to his second wife's son, who also seems to receive preferential treatment.

Mr. B's paradox was that in spite of all the difficulties and frustrations, he retained much personal charm and continued to love life "I simply love life and when I wake up at five o'clock in the morning and open the blinds so that the plants can get some light, I am happy" He said. Until his last year of life Mr. B enjoyed the benefits of above-average resources, particularly in the cognitive, social, economical and psychological domains. At the age of 95, they were waning. He felt that his cognitive abilities are declining. He was 
sometimes confused, he kept reading the daily and weekly papers in English, but his interest was waning. The computer was no longer a tool linking him to the world, giving him a feeling that he was in control. He became much more anxious, very disturbed by the loss of control, flooded with obsessive negative thoughts that he could not neutralize, and his emotional well-being was not as high as it was in the distant past. Mr. B has reached his architectural, biological, psychological and cultural end. He was no longer able to fight human nature, biology. Despite his high and well-preserved cognitive capabilities, his emotional behavior was characterized by a greater dependence, by demands, by a strong attachment to his wife and fears of separation, as well as lack of trust, which lead to negative feelings and depression. Mr. B unconsciously solved the problem through the paranoid schema. He placed the responsibility on the handsome young man who was full of life, potent, like a red flag in front of a bull, all of which only serve to emphasize the fact that he himself is old and lacking in virility. Having this young enemy made it possible for him to cope with the rejection from his wife - her son was responsible for all this, and not old age. It seems that the paranoia made it possible for him to continue living, and provided meaning to his life. However, the daily frustrations of his existence continued, and therefore, he kept on directing those feelings at his young wife, jealous of her physical independence and her sexuality. As a person and a therapist I wonder sometimes what keeps a man in his condition alive. How can he live with conflicting feelings of love for life and enjoyment gained from caring for plants, feelings of optimism, wisdom, wittiness, a sense of humanity, alongside feelings of unease, anger, demands, suspicions, criticism of the woman who is caring for him with such dedication, but who, as he kept on saying, was the love of his life. "The paradox of Mr. B" is perhaps the paradox of many oldest-old and the most significant challenge for survival. Medicine prolongs life but it is not enough for those who still want much more - who want to continue to taste life, to love, to feel loved.

\section{Conclusions and implications}

When physical and mental decline generate symptoms of paranoia the solution is in most cases anti-psychotic treatment. The question to be asked is what besides medication can be done. Medical treatment can reduce the symptoms but can also drug old patients to ease anxieties and agitation. It is evident that for most of the cases, this treatment calms the caregivers, the practitioners, the family, but does not necessarily improve the psychological inner turmoil of the very old adult. As Baltes \& Smith ${ }^{4}$ alleged, in the final stage, there is nothing more that can be done. We as practitioners are limited, and can only be there to support the delusional patient. To reassure him that we accept his feelings and help reduce the anger and frustration with minimal intervention as suggested ${ }^{11}$ Our role as therapists is to be with the person's "drama", to listen carefully and respect their anxieties and frustrations. To understand the narrative behind the delusional jealousy and to give some comfort by providing secure base, feelings of empathy and care. The other role is to provide the family and the caregivers with psychoeducation, understanding of the narrative behind the paranoia and the struggle that many of these old people have to fight against the losses of old age, to keep their respect, independence and sanity. Other goals include helping the caregivers to increase their frustration tolerance while caring for the old and sick. To practice coping skills in a complex situation by focusing on the positive perceptions of the old person and the important role of a caregiver. ${ }^{19}$ Treatment of the oldest old represents a challenge to mental health practitioners, who need specific knowledge and skills to work effectively with this age group and especially subgroup of older persons who suffer from paranoia. Moreover, our greatest challenge as mental health therapists is to be able to endure the mutual frustration and especially not to be afraid. Our goal is to continue to be there for those who are in the sad process of leaving life, like Mr. B and the members of his generation. Our abilities are limited. It seems that only warmth and love, good nursing care, preferably at home, in familiar and pleasant surroundings can ease, if only slightly, the final separation process.

\section{Acknowledgements}

None.

\section{Conflict of interest}

The author declares that there is no conflict of interest.

\section{References}

1. Dunkle R, Roberts B, Hang M. The oldest old in everyday life: Selfperception, coping with change, and stress. New York: Springer Publishing Company; 2001

2. Johnson CL, Barer BM. Life beyond 85 years: The aura of survivorship. New York: Springer; 1997.

3. Baltes PB. On the incomplete architecture of human ontogeny: Selection, optimization, and compensation as foundation of developmental theory. Am Psychol. 1997;52(4):366-380.

4. Baltes PB, Smith J. New frontiers in the future of aging: From successful aging of the young old to the dilemmas of the fourth age. Gerontology. 2003;49(2):123-135.

5. Johnson C, Barer B. Coping and a sense of control among the oldest old. Journal of Aging Studies. 1993;7(1):67-80.

6. Smith J, Baltes PB. Profiles of psychological functioning in the old and oldest old. Psychology and Aging. 1997;12(3):458-472.

7. Cohen-Mansfield J, Poon, LW. An Integrative summary and future directions in the study of well-being. In: Cohen-Mansfield J, Poon, editors. Understanding Well-Being in the Oldest Old. Cambridge: University Press;2011:364-377.

8. Ceglowski J, Vergel De Dois, Depp C. Psychosis in older adults. In: Pachana NA, Laidlaw D K. editors. The Oxford Handbook of Clinical Geropsychology. London: Oxford Press;2014:490-303.

9. Gurian BS, Wexler D, Baker EH. Late-life paranoia: Possible. Journal of Geriatric Psychiatry. 1992;7(4):277-284.

10. Ruskin P. Schizophrenia and delusional disorders. In: Bienfeld D, editor. Verwoerdt's clinical geropsychiatry. Baltimore: Williams \& Wilkins;1990:125-136.

11. Hashimoto M, Sakamoto S, Ikeda M. Clinical features of delusional jealousy in elderly patients with dementia. Journal of Clinical Psychiatry. 2015;76(6):691-695.

12. Zarit SH, Zarit JM. Mental disorders in older adults: Second edition. New York: The Guilford Press; 2007.

13. Molinari V, Chacko R. The classification of paranoid disorders in the elderly: A clinical problem. Clinical Gerontologist. 1983;1(4):31-37.

14. Bar-Tur L, Sandler AM. Problem in psychoanalysis of an aging narcissistic patient. Geriatric Psychoanalysis. 1978;11:5-36.

15. Sandler AM. Problems of development and adaptation in an elderly patient. Psychoanalytic study of the child. 1984;39:471-489. 
16. Gutmann D. Reclaimed Powers. Illinois: Northwestern University Press; 1994.

17. Bowlby J. A secure base: Clinical applications of attachment theory. London: Rutledge; 1988.

18. Miller E. The Oedipus Complex and rejuvenation fantasies in the analysis of a seventy-year old woman. Journal of Geriatric Psychiatry. 1987;20(1):29-51.
19. Malkinson R, Bar-Tur L. Bereavement and grief work. In: Pachana NA, Laidlaw DK, editors. The Oxford Handbook of Clinical Geropsychology. London: Oxford Press; 2014. 